\title{
Cholera Outbreak in Gaidataar: A Lesson for Further Strengthening the Task Force for Epidemic Management in Nepal
}

\author{
Sachin Yadav' \\ 'Lunkhu Primary Health Centre, District Health Office, Parbat, Nepal.
}

\begin{abstract}
Cholera is an acute enteric infection caused by the ingestion of bacterium Vibrio cholerae ${ }^{1}$. Cholera is transmitted through contaminated food and water. Prevention and preparedness of cholera require a coordinated multi-disciplinary approach. The extremely short incubation period enhances the potentially explosive pattern of outbreaks. Cholera can lead to severe dehydration and death if left untreated. The laboratory testing is required for antimicrobial sensitivity testing and for confirming the end of an outbreak. Provision of safe drinking water, proper sanitation, and food safety are critical for preventing occurrence of cholera. Health education aims at communities adopting preventive behavior for averting contamination. Specific training for all the staffs about proper case management including avoidance of noso-comial infection (like face masks, gloves, antiseptic solution, hand scrubs). Sufficient pre-positioned medical supplies for case management (diarrhoeal disease kits, iv fluids, antibiotics, safety measures). Improved access to water, effective sanitation, proper waste management and vector control. Improved communication and public information. Oral Rehydration Salts can treat $80 \%$ of cholera ${ }^{1}$. Appropriate antibiotics can reduce the duration of purging. With a well and properly managed team of health experts with all essential medicines and a good rapid response team, any outbreak can be prevented, controlled and managed.
\end{abstract}

Keywords: cholera; epidemic; ORS; rapid response team; shanchol; task force.

\section{INTRODUCTION}

Cholera is an acute enteric infection caused by the ingestion of bacterium Vibrio cholerae present in fecally contaminated water or food. It is primarily linked to inefficient access to safe drinking water and proper sanitation. Its impact can be even more dramatic in areas where basic environmental infrastructures are disrupted or have been destroyed. ${ }^{1}$

Countries facing complex emergencies are particularly vulnerable to cholera outbreaks. Massive displacement of IDPs or refugees to overcrowded settings, where the provision of potable water and sanitation is challenging, constitutes also a risk factor. ${ }^{2}$ Cholera is characterized in its most severe form by a sudden onset of acute watery diarrhoea that can lead to death by severe dehydration. ${ }^{3}$
The extremely short incubation period two hours to five days enhances the potentially explosive pattern of outbreaks, as the numbers of cases can rise up very quickly. ${ }^{4}$ Cholera is an extremely virulent disease that affects both children and adults. ${ }^{2}$ It can kill healthy adults within hours. A cholera epidemic identified at Gaidataar, Chandranigahpur VDC-3 and 4, Rautahat.

\section{CHOLERA OUTBREAK IN GAIDATAAR}

Gaidataar, Chandranigahpur VDC- 3 and 4 (now Chandrapur Municipality-3), Rautahat has shown a

Correspondence: Dr. Sachin Yadav, Lunkhu PHCC, District Health Office, Parbat. Email: drsachinrajyadav@gmail.com, Phone: +977-9857654945. 
periodic outbreak of Acute Diarrheal Diseases for long time back and has occurred such outbreaks in 2061 B.S., 2068 B.S., and recently in 2071 (Baisakh 16 to Asar 31-2071). The major cause of such outbreaks time and again are unavailability of safe drinking water, habit of open defecation, seasonal drought and heavy rainfall, lack of knowledge of proper sanitation, unawareness about the spread of such diseases, among the inhabitants of that area. And also lack of efficient Rapid Response Team (RRT) operating through District Health Office (DHO), Rautahat.

The outbreak of Acute Diarrheal Disease was informed through EWARS (Early Warning And Reporting Systema unit of RRT, Rapid Response Team) on 16 Baisakh 2071 evening. On very same evening two diarrheal cases were attended and admitted at Chandranigahpur Hospital (Government of Nepal). The following morning, a small unit (comprising a Medical Doctor, a paramedic, a nursing staff, two peons, a lab technician) with ORS, all the essential medicines and IV fluids were sent to the area. A temporary diarrheal management camp was set up in the affected area with the help of local inhabitants.

\section{CASE ANALYSIS}

There were 118 patients of diarrhoea with varying degree of dehydration. Most of them were treated and provided with ORS, and asked to follow up very next day but few were kept in that temporary shelter and IV fluids were started together with oral rehydration. The very next day the camp was shifted to local Vaccination Centre of the area (managed by then Local Administration with one AHW and one ANM). The number of case kept on decreasing on the subsequent days but surprisingly few patients came with repeated infection after 2-3 days and then we (Chandranigahpur Hospital Administration) decided not to withdraw from the site suddenly rather to remain there in some form and continue the treatment and shifted the camp to a high School (Shri Janashakti Ma. Vi. Gaidataar). The camp remained there till 31 st Baisakh.

Due to gradual decreasing the number of cases we were planning to withdraw the camp when we were informed about a sudden demise of a child aged $5 \mathrm{yrs} /$ Female inhabitants of upper part of Dhimal VDC (which is part of Makwanpur District) and then we again decided to contiue the camp and together all health education about the disease and the sanitation and good food hygiene were also done. Communities were reminded of basic hygiene behaviors, including the necessity of systematic hand washing, with soaps after defecation and before handling food or eating as well as safe preparation and conservation of the food. Appropriate media Radios (local FM and national Radio), TVs, newspapers were involved in disseminating the health education messages. A team from Central Regional Health Directorate, Hetauda headed by the Director (Dr. Anand Shrestha) himself visited the site and a small workshop was conducted with all the stakeholders in the district and work plan was designed. Strengthening surveillance and early warning was followed to diagnose the first case (by clinical) and then laboratory techniques (NPHL, Teku). A total 1814 acute diarrhoeal cases were attended since onset of the outbreak (16 Baisakh 2071) till the time when the outbreak was totally under control (31st Asar 2071).

The presence of Vibrio cholerae in stools was confirmed through laboratory procedures ${ }^{5}$ (from National Public Health Laboratory, Teku). A team of health experts through EDCD (3 Post Graduate Students of Community Medicine, a senior lab technician) visited the area and collected 8 samples of stools from diarrhoea affected individuals(patients) and 8 samples of water from different water sources (which had been used by the community) collected and brought to NPHL, Teku. and the report from NPHL shown 4 samples of stools contained Vibrio cholerae stain 01, and 0139. Eight samples of water showing full of coli forms bacteria suggesting not suitable for drinking purpose. Report had also commented on the sensitivity of the drugs (antibiotics) used for the treatment purpose, citing pathogens sensitive to Cotrimoxazole, Azithromycin etc. but resistant to Nalidixic Acid (which we hadn't used). We didn't have access to any RDT (Rapid Diagnostic Technique).

\section{INITIATIVES TO SOLVE THE PROBLEMIS FOR LONG TERM CONTROL}

Among people developing symptoms, $75 \%$ of episodes were mild or moderate severity. The remaining 15$25 \%$ of cases developed severe watery diarrhoea with signs of dehydration. Once the outbreak was detected and confirmed by laboratory examination intervention strategy was aimed to reduce the mortality and ensuring access to treatment and controlling the spread of the disease $^{2}$. All the partners involved (Chandranigahpur Hospital, DHO Rautahat, WHO-IPD Hetauda, WHO-IPD Janakpur, UNICEF, Nepal RED-CROSS Society, DAO Rautahat, AAO Chandrapur, APO Chandrapur, DDC Rautahat, WASSO Rutahat, etc.) were made engaged in the effective way to control the outbreak and manage the cases so far seen.

\section{CASE MANAGEMENT}

Efficient treatment was done by prompt rehydration through the administration of Oral Rehydration Salts (ORS) and also by intravenous fluid (depending upon the severity of the dehydration). Up to $80 \%$ of the 
patients were treated adequately through administration of ORS (WHO/UNICEF ORS standard Sachet). ${ }^{2}$ Very severely dehydrated patients were treated through administration of Intravenous Fluids Preferably Ringer Lactate. Antibiotics were also used for severely dehydrated patients who didn't recover after 2 days of ORS and IV fluids treatment. ${ }^{2}$ After use of antibiotics we found: decrease in duration of diarrhoea, reduced volume of rehydration fluid required per per patient and also shortening the duration of $\mathrm{V}$. cholera excretion. For children, up to 5 yrs of age, supplementary administration of Tab. Zinc was done which proved to be effective in reducing duration of diarrhoea as well as reduction of successive diarrhoea episodes. ${ }^{2}$ To ensure timely access to treatment, Cholera Treatment Centres were set up in the affected community (in a High School: Shri JanaShakti Ma. Vi. Gaidataar, Rautahat).

\section{CHOLERA VACCINES}

Shanchol is an oral vaccine for cholera was used for post exposure prophylaxis to the affected population after the outbreak was fully under control. ${ }^{1}$ The vaccination was done two stages in 1 (4 weeks) month apart. A WHO sponsored vaccine launched for the first time in Nepal. First phage was conducted from Bhadra 3 to 4 2071, then Second phage was conducted from Asoj 2 to 3 2071. Doses: 2 drops per oral with $150 \mathrm{ml}$ of water. People excluded are: child $<2$ yrs and adults $>65$ yrs, pregnant ladies, people living with chronic diseases.

\section{WAY FORWARD}

Epidemic outbreak is common in Nepal, if not controlled in time it leads death of thousands of people every year so we need to strengthen the National Task Force to prevent, control and manage it on time. Prevention and preparedness an epidemic outbreak is a multidisciplinary approach and needs involvement of all the stakeholders for providing control measures such as improved water supplies, adequate sanitation and health education and management of any outbreak.

With a well and properly managed team of health experts with all essential medicines and a good rapid response team, any outbreak can be prevented, controlled and managed. It's recommended to improve surveillance system to obtain better data for risk assessment and early detection of outbreaks, including establishing an active surveillance system.

\section{ACKNOWLEDGEMENTS}

I would like to thank the WHO country office for Nepal, UNICEF, MOHP, DoHS, DHO Rautahat for their support.

\section{REFERENCES}

1. Detels, Rogers; Beaglehole, Robert; Lansang, Mary Ann; Gulliford, Martin. Oxford Text Book of Public Health, 5th ed. Oxford, UK: Oxford University Press; 2009. 228 p.

2. World Health Organisation. Cholera. [updated 2017 August; cited 2017 Sep 01]. Available from: http://www.who.int/ mediacentre/factsheets/fs107/en/ [Full Text]
3. Kasper D, Fauci A, Hauser S, Longo D, Jameson JL, Loscalzo J. Harrison Text book Of Internal Medicine, 19th Ed. USA: McGraw Hill Education; 2015. 660 p.

4. Park K. Park's Text Book of Preventive and Social Medicine, 23rd ed. India: Banarsidas Bhanot Publishers; 2015. 320 p.

5. Ananthnarayan R; Jayaram PCK. Ananthnarayan and Paniker's Text book of Microbiology, 9th ed. India; 2013. 220 p. 